\title{
Sick and Vulnerable Migrants in French Public Hospitals. The Administrative and Budgetary Dimension of Un/Deservingness
}

\author{
Jérémy Geeraert
}

Institute for European Ethnologie, Humboldt University Berlin, Germany

E-mail: geeraert.j@gmail.com

This article explores how staff in French public hospitals are indirectly involved in the governing of migration through healthcare. It unpacks the construction of differentiated values of life assigned to specific categories of vulnerable (authorised and unauthorised) migrants according to their perceived un/deservingness in context of budgetary restrictions. This context emphasises tensions between medical and administrative staff in the decision-making process regarding access to healthcare. The analysis rests upon empirical data (participant observations and semi-directed interviews) gathered in 'healthcare access units' located in public hospitals. Perceptions of un/deservingness lead to both healthcare rationing and healthcare denial and are built upon entangled criteria related to both migration status and budgetary concerns. These mechanisms reveal the administrative and budgetary dimensions that underlie the perceptions of health-related un/deservingness, which is linked to the costs of healthcare: the higher the costs, the less likely patients are to be designated to be deserving of healthcare.

Keywords: Deservingness, migration, healthcare system, public hospital, value of life.

\section{Introduction}

Thinking about how migration is managed in the present-day global north demands a consideration beyond either the spectacle of the border (De Genova, 2002) or a simplistic binary analysis in terms of exclusion and inclusion (Geeraert, 2018). Modern forms of governing migration are instead characterised by differential inclusion and by internal borders, both of which occur in various forms, places, and temporalities within nationstates (Mezzadra and Neilson, 2013). For instance, the production of the state of illegality and of numerous sub-categories of legal status has, since the 1970s, been entangled in the processes of the contraction of the social state through the appropriation of categories produced by the administration of migration. Instead of formal exclusion or inclusion in relation to welfare benefits, one can instead observe a more subtle and multi-faceted 'curbed inclusion' ('inclusion bridée', Chauvin, 2009) emerging from migration policies and becoming infused in all spheres of society through the (still) strong regulatory power of the welfare state.

This article focuses on the area of healthcare provision and looks into the tensions and dynamics involved in the inclusion and/or exclusion of migrants from healthcare services. More precisely, it explores the role of street-level agents ${ }^{1}$ (Lipsky, 2010) and hospital managers in the government of migration through their activity in French public hospitals. Through their praxis, hospital employees (e.g. physicians, hospital managers, social 
workers) draw the lines of informal and internal bordering practices, which focus on sick bodies. It results, in the context of budgetary constraints within French public hospitals (Juven et al., 2019), in the construction of differentiated values of life based on notions of deservingness and undeservingness, both of which are assigned to specific categories of sick migrants who are either unauthorised or have a precarious legal status. The notion of health-related un/deservingness is understood as involving 'divergent and often competing moral stances about whose health - whose bodies, lives, and life chances - matters' (Willen and Cook, 2016: 95). While most scholars have focused on the moral construction of the notion of deservingness (Chauvin and Garcés-Mascareñas, 2014; Yarris and Castañeda, 2015; Willen and Cook, 2016), this article tackles it from another angle and unpacks the structural elements, such as the administrative and budgetary dimension, upon which the moral stances are largely constructed. In other words, the results of this research show that the moral assessment of health-related un/deservingness is greatly influenced by pre-existing reduced possibilities of action.

The first part of the article focuses on the methods and theoretical framework used. The two following sections are devoted to the analysis of the empirical material. I first explore how categories of vulnerable migrants are constructed based on their (lack of) potential entitlement regarding public healthcare and how professionals ration this healthcare based on these categories. In the last part, I examine the case of the most undeserving category (the 'therapeutic migrant') which results in a total exclusion from the healthcare system.

\section{Methods and presentation of the study}

The analysis rests upon empirical data gathered over a three year period in sixteen 'healthcare access units' (permanences d'accès aux soins de santé, PASS) located within public hospitals in different cities in France. It looks at the everyday interactions between healthcare practitioners, hospital managers, and patients at the more marginalised end of the healthcare system and the related construction of moral un/deservingness through these interactions. Data were collected through in-depth interviews $(n=40)$ and participant observations conducted between 2011 and 2014 with healthcare professionals working in PASS. The extensive ethnographic component was undertaken in two hospitals, one in Paris and the other in a lower socio-economic Parisian suburb. ${ }^{2}$

PASS aim to facilitate access to healthcare and to health-related rights for people that are situated at the margin of the healthcare system. Most PASS patients are vulnerable people who have no healthcare insurance, thus no access to the healthcare system. Since PASS patients have no insurance, the costs of their healthcare have to be borne by the hospital itself, while for all other insured patients the costs are charged to the medical insurance system. Most of PASS' patients are vulnerable migrants (either authorised or unauthorised, e.g. asylum-seekers, migrants on tourist visas, poor citizens of other European Union countries, etc.). In order to make reading easier, these groups are referred to by the generic term 'vulnerable migrants'.

PASS have been implemented in French public hospitals since 1998. The primary goal of these units was both to encourage social inclusion and to reduce the amount of unpaid bills generated by destitute patients without healthcare insurance. The aid is distributed on a case-by-case basis in the form of a voucher that enables the patient to access healthcare free of charge within the hospital. There are no clear guidelines 
regarding eligibility criteria for the aid, so there are various local rules (both formal and informal) and there is a certain amount of room for manoeuvring within the decisionmaking process. In order to benefit from PASS, patients usually must first see the social worker who conducts an initial assessment. If the patient meets the formal (lack of healthcare insurance and assessment of poverty) and informal (based on the local moral order of un/deservingness, see Geeraert, 2016) criteria, she/he will be able to access the general practitioner who conducts a medical and social examination. The access to PASS is never guaranteed and can be refused at any time if it appears that the patient does not fulfil either the formal and informal conditions constructed in the local PASS.

\section{Institutional frame of migrant un/deservingness in the French healthcare system}

For a thorough analysis of the structural elements underpinning the moral assessment of a migrant's un/deservingness, the field of healthcare seems to be particularly fruitful. Since the 1970s French social security has gone through numerous reforms which have led to the introduction of distinct administrative categories of vulnerable migrants borrowed from the migration control policies. ${ }^{3}$ Characteristic of this evolution is the multiplication of stratified and differentiated health programs with lower levels of healthcare coverage (Geeraert, 2018). For example, a few years after the creation in 1998 of a specific healthcare coverage program for unauthorised migrants (Aide médicale d'Etat, AME), there were harsh criticisms raised against this program for allegedly being a 'pull factor' for migration. These criticisms led to the narrowing of the conditions for accessing AME in 2003 (Izambert, 2014). This reform and others have produced new categories of migrants within the healthcare coverage system (e.g. 'unauthorised migrant in France for less than three months', 'poor EU citizens') that have been excluded from all forms of healthcare coverage. They are called, within the healthcare administrative field, 'patients without potential entitlement'. Because of the multiplicity and the complexity of the healthcare protection system at its lower end, other vulnerable migrants are also uninsured, although they may in fact be eligible; they are referred to as 'patients with potential entitlement'. In order to avoid dramatic situations, and adhere to human rights protections enshrined in law, a program called the 'urgent and vital healthcare fund' (fonds soins urgents et vitaux) has been instituted that offers an even narrower protection (i.e. only in cases where biological life is threatened) for the uninsured patient with or without potential entitlement. This program was instituted as a result of a similar logic to that which justified the creation of PASS in public hospitals in 1998 (offering limited healthcare for people without healthcare insurance).

Although the reality of everyday praxis is blurrier as we will see below, the lower end of this stratified healthcare coverage system seems to draw two red lines which are not supposed to be crossed: a) a principle of bio-legitimacy (which acknowledges a sacred and universal dimension of the human life, see Fassin et al., 2001); and b) the protection of the public from infectious diseases such as HIV or tuberculosis (Geeraert, 2018). These narrow criteria for healthcare coverage act as government tools - one can say as bio-powers ('that make live and let die', Foucault, 1997: 214) - fulfilling public health and human rights obligations, while simultaneously curbing social inclusion. ${ }^{4}$ This stratification of the healthcare coverage system at its lower end therefore provides a glimpse into the construction of differentiated conceptions of 'life worth protecting' at a structural level - one that is 
directly linked to subtle criteria of citizenship and migration policies. These differentiated conceptions are the structural context from which different levels of health-related un/ deservingness are morally constructed by street-level healthcare professionals in PASS.

\section{Assessment of health-related un/deservingness in PASS}

\section{The entanglement of un/deservingness with legal status and budgetary concerns}

Ranging from a rationing of, to an exclusion from, healthcare, PASS has many ways of differentiating the distribution of healthcare protection according to citizenship categories. For patients who are not eligible for any healthcare coverage at the time of their initial visit, PASS appears to be the only place to access public healthcare. However, the healthcare available for them through PASS is limited and is subject to constant rationing and bargaining, especially if the costs are high. Because the costs of healthcare for PASS patients are covered by the hospital itself through a state subsidy (and not by insurance as for patients with coverage), these costs become hyper-visibilised in a context of budgetary pressure. Therefore, the necessity of each occasion of treatment or care is evaluated and related to the legal situation of the patient. Although there are no official rules establishing who is entitled to each level of healthcare, one can still observe informal rules which are based on the entanglement of the perceived un/deservingness of the patient, their legal status, and the costs of the treatment.

\footnotetext{
Right, people who come to France to give birth. At some point, we can't prevent them coming to give birth, but they will get a bill, so I don't care. You know, it's complicated. You can't come to give birth and go away 'bye, I don't have a health insurance'. [ ... ] At some point, we had a lot of them, but after a while, not anymore. Because, when we say to them that if they have a [tourist] visa, they will receive the bill [from the hospital], the people don't come much anymore. We explain them that we can't do anything for them, that they will receive a bill which they have to pay. (Interview with the head of the social work department, Hospital A, Parisian suburb)
}

In this excerpt, the head of the hospital's social work team (non-medical staff) who is in charge of the local PASS explains that they have an (informal) rule that does not authorise payment for midwifery services for patients with a valid tourist visa. Patients with tourist visas are often excluded based on the argument that PASS is meant for people living in France and not for 'tourists'. Although it is not a formal rule, there is a common understanding that PASS is an aid program intended for people who already belong to the national community (and not for newly arrived foreigners). This undeserving moral figure of the cheater is therefore joined with a particular legal category (tourist visa holder). As a result, he/she is deprived of any possibility of healthcare services through public healthcare insurance ('without potential entitlement') and the hospital would be required to cover all costs if the patients cannot pay him/herself.

In this context, PASS professionals use negative moral categories of undeservingness in order to deny access to patients whose legal situation would generate the highest costs for their hospital. Patients with tourist visas are the category that has the least 'potential entitlement'. It is the only category that is not eligible for the 'urgent and vital healthcare fund' and is also the one constructed as the most undeserving in PASS. On the other hand, 
the more likely that patients have a potential entitlement, and are theoretically billable, the more likely that PASS professionals consider them as deserving to receive healthcare through PASS.

For the patients categorised as undeserving, the risks of being denied access to PASS, or of receiving only limited healthcare, is higher than for other patients. When they are granted the access to PASS, this access will often be limited to primary care or low-cost care. The higher the costs, the lower the deservingness of the patient 'without potential entitlement' to access healthcare.

Participant: [Regarding patients with tourist visas] We will try to see with the [travel] insurance. But it depends also what the patient wants. You see, if it's to see... If the patient has a [tourist] visa and he wants to see an ophthalmologist! Fuck, it's his business! I'm sorry, but at some point...

Interviewer: So this patient will not be granted access to PASS.

Participant: No, here it's comfort. PASS isn't meant for that. I mean we'll tell him to pay, I'll not prevent him from accessing to the consultation.

(Interview with the chief of the social service department, Hospital A, Parisian suburb.)

This interview excerpt shows how differentiated values are constructed according to criteria based on legal residency status and are framed in moral categories of the deserving or undeserving patient. For the less legitimate patients, professionals may distinguish between healthcare services that they see as elective ('comfort') and healthcare services that are 'necessary'. While for any other patient it would be rather unusual for nonmedical staff to express an opinion about the medical needs of a patient, social workers commonly evaluate the deservingness of migrants 'without potential entitlement' in relation to the health-related services they are seeking. What is seen as elective healthcare is not included in the value of life worth protecting for patients on tourist visas.

\section{The calculation of the value of life}

The calculation of this value can take place at many levels and is the object of negotiations. At University Hospital B (in a Parisian suburb), these elements became obvious in a discussion between healthcare professionals about PASS patients that have been sent to the hospital ophthalmologist because of a condition causing loss of sight. The ophthalmologist received the patient without knowing that they were PASS patients and thus uninsured. After the examination he prescribed a treatment for the patient to pick up at the hospital pharmacy. However, instead of dispensing the treatment to the patient, the hospital pharmacist wrote an email to the chief-administrator of PASS, also copying in three different members of the hospital management (head of the social work team, the quality director, and the chief financial officer [CFO]), as well as the ophthalmology unit), asking if he was aware how expensive these prescriptions were, and exposing the prices of the different drugs. The chief-practitioner of PASS answered (to all):

I'm not aware of these prescriptions. It seems to me that we can't refuse a treatment, including when it is expensive, if it is necessary. However, it has long been agreed that treatments which can 
be delayed while awaiting the insurance to come can be delayed, as long as it does not expose the patient to consequences of extreme gravity. It should be checked if this is the case here.

The ophthalmologist responded by prudently justifying his prescription with the official recommendation of the French Society of Ophthalmology and added at the end:

Our problem is that we do not always have the information that the patient does not have a healthcare insurance and gets his/her medicine from the hospital pharmacy. I think that we have to check on a case-by-case basis if it's an emergency or not.

This exchange of emails reveals two important elements of the ongoing socialisation process, which constructs differential values of life worth protecting for vulnerable migrants in public hospital.

Firstly, it involves a number of actors - an administrator of PASS, the hospital pharmacist, an ophthalmologist, the head of the hospital social work team, the quality director, and the CFO. Some of these actors exert a silent power of control and some others empirically construct (or improvise) a reduced value of life worth protecting for PASS patients. The ongoing negotiation between these actors involves, on the one hand, medical doctors whose argumentation principally relies on medical standards constructed within the profession and, on the other hand, managers and paramedical actors. In this example, the pharmacist is pulled between the request of saving money made by hospital managers (in the copy of the email exchanges) and her subordinate position regarding the medical authority. The way medical professionals prudently justify their prescription is a clear sign of their declining authority in the context of growing new management in public hospitals (Evetts, 2013) and of the central role of budgetary saving in access to healthcare for vulnerable migrants through PASS. In this context, non-medical staff members interfere with the medical decision-making process. The example also reveals the uneven distribution of powers in the negotiation, in which not only the vulnerable migrants are subordinate, but also the medical professionals. This subordination is subtle and does not result from a direct confrontation between hospital managers and medical professionals. On the contrary, it is through the pharmacist who has been urged to reduce costs that the budgetary pressure is coming. If the medical justification for the treatment still surpasses the question of its cost, it tends to give a more central place to the financial dimension of the medical practice.

It is important to stress that the assessment of un/deservingness for vulnerable migrants is indirect. The reason why healthcare is rationed for these patients lies in the combination, on the one hand, of budgetary pressures (and new public management strategies) and, on the other hand, the exclusion of particular categories of vulnerable migrants from the national healthcare insurance (meaning that costs for these patients have to be borne by the hospital itself). The patients are excluded because they are uninsured and they are uninsured because they are migrants; this relation is built in such a manner that the rationing becomes an indirect form of governing migration by assigning lower healthrelated deservingness to particular categories of people.

Secondly, for some undeserving categories of vulnerable migrants from PASS the life worth protecting is subject to negotiation as soon as the treatment requested is expensive. In the situation described above, one can see that medicine to prevent loss of sight is subject to debate, mostly because it is expensive. As the ophthalmologist clearly writes, it would not 
be an issue for regular patients who have a healthcare insurance - the differential treatment is only for categories of vulnerable migrants, and so it draws the contours around the concept of deservingness. The questions raised in this discussion are: is it a medical emergency? Would the patient experience a loss of opportunities if he/she did not receive the treatment? These questions reveal the tensions between budgetary concerns and 'biolegitimacy', a principle that attributes a superior value to biological life and its protection (Fassin et al., 2001). Parting from a minimum understanding of life as biological - and not as containing social and political dimensions - the negotiation tends to delineate what is the minimum necessary to respect the biological integrity of the vulnerable migrants which is measured in terms of 'consequences of rare gravity' or 'urgent treatments'. This negotiation tends to empirically produce at the local level a category of under-patients whose lives are considered to deserve less protection than others.

\section{The therapeutic migrants and the questioning of the bio-legitimacy principle}

In the PASS at University Hospital C (Paris), professionals have encountered difficult situations involving a specific category of patients that I refer to as 'therapeutic migrants'. These patients are vulnerable migrants who travel to France specifically to seek treatment for a severe disease, which would not be possible to obtain in their country of origin. However, because of this specific goal, these vulnerable migrants have very few chances of ever being granted access to healthcare coverage in France. Therefore, for most of these patients, it will ultimately be up to the hospital to bear the costs of their expensive treatment. While this phenomenon has largely been ignored at a political level (Mbaye, 2009), its materialisation appears strengthened at the local hospital level where it raises a dilemma between the medical-moral obligation of healthcare and economic constraints (especially in a context of budgetary pressure).

At University Hospital C, the medical director of PASS decided to create a multidisciplinary consultation meeting on ethical, medical and social issues, which is called by its acronym RCP-MSE (Réunion de concertation pluridisciplinaire - medico, sociale et éthique) in order to respond to this dilemma. Progressively, the RCP-MSE has become a tool for making decisions about whether or not to treat therapeutic migrants in Hospital C, and, more broadly, elsewhere in France. A negative decision was made by the RCP-MSP concerning patient $M$, an Armenian, aged thirty-three years, who came to Hospital $C$ for treatment of a rare cancer that had caused paralysis of his legs. During the meeting, discussions included the social situation of the patient in France, the available treatments and their potential costs at Hospital C, and the treatment options he had in his home country. The RCP-MSE concluded that, 'taking all these elements into account, there is no obligation [légitimité] for this patient to be provided care in France. It thus appears to be preferable for the patient to pursue his healthcare in his country of origin' (excerpt of the minutes). The focal point of the meeting had been the budgetary matters related to the deservingness of therapeutic migrants to be treated 'free of charge' in Hospital C, and more broadly in France. In addition to the cost of the treatment, the negative decision has been justified because the patient ostensibly had the option of accessing treatment in his country of origin, and also because his disease was chronic (and thus not curable).

A crucial turning point in the organisation of these meetings had been the invitation by the medical director of PASS, in 2012, to the hospital CFO and the managers of the 
financial department, to participate to these meetings on a regular basis. RCP-MSE thus became a tool that aimed to regulate, at the local hospital level, access to healthcare for therapeutic migrants by excluding the less deserving with an underlying goal to rationalise hospital expenses. The street-level healthcare professionals on the one hand, and the managers on the other hand, have become 'moral entrepreneurs' (entrepreneurs de morale, Dubois, 2003: 75) regarding a certain type of migration related to health that is seen as un/deserving in relation to receiving healthcare in France.

In the minutes of another meeting of the RCP-MSE, a reflection was developed:

The question of the value of justice is strongly asked in this situation. It compels us to consider the prejudice that this situation could generate for other patients, the 'invisible others' ('tiers invisibles') in the healthcare relationship. It draws attention to the tension between a humanitarian view and the economical rationality. To include this patient in a healthcare program 'free of charge' in France could be considered as inadmissible from a social justice perspective.

It is through the internalisation of the necessity to save money in a context of budgetary pressure that the refusal of these therapeutic migrants is justified. The RCP-MSE is a laboratory undertaking experiments with the fictional limitation on the resources of PASS, and thereby justifying refusal of healthcare. However, there is, in reality, no limit on the budget for PASS since legal texts specify that their expenditures are part of the general expenses of the hospital. The reason for the resulting exclusion requires an understanding of the benefit/cost relation between the economic costs of the treatment, the advantages that it would bring for a specific patient, and the hypothetical shortage that the costs would generate for future patients (i.e. if you give more to this patient, the other patients will receive less). It is obvious here that the decision made during the RCP-MSE is not only a medical decision, but much more a political decision regarding the legitimacy of a particular type of migrant, and is related to budgetary considerations (far removed from a typical medical decision making). It draws attention to the traits of health-related deservingness among therapeutic migrants that are negotiated between street-level healthcare professionals and the hospital managers who have appropriated discretionary power in the management of this type of migration.

To some extent, it is a similar phenomenon to the one described by Spire (2008) about street-level bureaucrats working in the French administration of migration (préfectures) among whom some pursue a 'moral crusade' (croisade morale) in which the rules are interpreted to serve what they see as either the national interest or maintenance of the national order. In the case of the RCP-MSE, the moral crusade is additionally entangled with the context of new public management. From this perspective, the discretionary power in the management of therapeutic migration serves both to protect the budgetary situation of the individual hospital as well as the national interest (and in particular the interest of the public healthcare system understood as jeopardised by the category of therapeutic migrants). The professionals involved in this local migration policy adopt an organisational model in which the discourse of enterprise becomes linked with discourses of professionalism, quality, customer service and care' (Evetts, 2011: 412). The RCP-MSE is presented as a tool that rationalises the potential expenses incurred by the hospital and a result of therapeutic migrants and not as a tool that constructs differentiated value of life for this migrant category. The logic of RCP-MSE - which sees healthcare for this category of patients as limited, and puts the migratory biography at the centre of the 
decision-making process - tends to invite the health practitioners to see the biological life of the patients as not deserving of being protected by the French healthcare system. By doing so, it questions the minimal health-related deservingness that is the bio-legitimacy benchmark since the concerned patients have life-threatening diseases and PASS represents their last access point to public healthcare.

\section{Conclusion}

Professional praxis in PASS determines different levels of un/deservingness regarding health protection for specific categories of vulnerable migrants. The more the deservingness shrinks, the less the biological life of the vulnerable migrant will be granted protection (going from a rationing of healthcare to the exclusion of the PASS). The level of deservingness is measured with categories borrowed from the migration control policies and which are used as condition of access to PASS for specific migrant categories (e.g. the distinction between patients 'with potential entitlement' and those without) and as criteria for healthcare rationing.

The moral construction of health-related un/deservingness in PASS is entangled with two main pillars: the exclusion of categories of vulnerable migrants from the healthcare coverage system on the one hand and, on the other hand, the organisational order of contemporary public hospitals (which rests upon the logics of new public management and budgetary saving). The observed spaces of negotiation in PASS show that hospital managers tend to be either directly or indirectly involved in the medical decision-making process and to bring budgetary considerations into an increasingly central place. This structure makes vulnerable migrants in particular more likely to be designated as undeserving in public hospitals, also in places such as PASS which have been created to protect them. In this context, decisions concerning the deservingness of vulnerable migrants to be protected through PASS have led professionals to produce different degrees of the bios - the life of the citizen increased with political and social dimension (Agamben, 1998). For patients 'without potential entitlement' - those for whom the hospital has to bear the costs itself - the bios worthy of protection tends to be reduced generating undercategories of patients. Also, the limits set by the bio-legitimacy principle (Fassin et al., 2001), which supposes to place the protection of the biological life above all, seems to be questioned, especially when the costs of treatment are high (as it is often the case for therapeutic migrants). The more patients belong to categories of migrants that have been kept away from the healthcare protection system, the more their condition tends to require expensive treatment, and the less these patients are morally read as deserving of benefiting from the protection of PASS.

Nevertheless, the construction of un/deservingness takes place at a local level, which makes it difficult to grasp. It rests upon disparate and often informal rules that are constructed by local actors (opposing medical staff and hospital mangers). The room for manoeuvre of street-level healthcare professionals and the negotiation power of the different actors involved still play a great role in the decision-making process.

By receiving patients who have been excluded from the rest of the public healthcare system, and therefore, as the last place of protection in a stratified healthcare system, PASS faces tensions between ethical and moral obligations (not to let people die) and budgetary pressures. For patients, it results in a form of curbed biological citizenship (Petryna, 2002), which is constructed, contested, negotiated, on a local level and framed in moral categories of un/deservingness. 


\section{Notes}

1 Public servants who are directly in contact with users. For more details see the introduction of this themed section.

2 The study was ethically approved according to the standards of the ethical board of the University Paris 13.

3 The French healthcare system is based on a social security system with a mix of public and for-profit medicine. It is based on a wide net of public and private insurance and a universal health coverage principle.

4 Also, it is important to emphasise that these public healthcare coverage programs for non-citizen and precarious migrants are not basic standards in the countries of the global north. Accessing basic healthcare for unauthorised migrants is a common problem in most of these countries (see FRA, 2011).

\section{References}

Agamben, G. (1998) Homo Sacer: Sovereign Power and Bare Life, Stanford: Stanford University Press.

Chauvin, S. (2009) 'En attendant les papiers. L'affiliation bridée des migrants irréguliers aux Etats-Unis?', Politix, 87, 3, 47-69.

Chauvin, S. and Garcés-Mascareñas, B. (2014) 'Becoming less illegal: deservingness frames and undocumented migrant incorporation', Sociology Compass, 8, 4, 422-32.

De Genova, N. (2002) 'Migrant 'illegality' and deportability in everyday life', Annual Review of Anthropology, 31, 1, 419-47.

Dubois, V. (2003) La vie au Guichet: Relation Administrative et Traitement de la Misère, Paris: Economica. Evetts, J. (2011) 'A new professionalism? Challenges and opportunities', Current Sociology, 59, 4, 406-22. Evetts, J. (2013) 'Professionalism: value and ideology', Current Sociology, 61, 5-6, 778-96.

Fassin, D., Costa-Lascoux, J. and Hily, M-A. (2001) 'L'altérité de l'épidémie. Les politiques du sida à l'épreuve de l'immigration', Revue Européenne de Migrations Internationales, 17, 2, 139-51.

Foucault, M. (1997) Il Faut Défendre la Société: Cours au Collège de France, 1975-1976, Paris: Gallimard. FRA, European Union Agency for Fundamental Rights (2011) Migrants in an Irregular Situation: Access to Healthcare in 10 European Union Member States, Leiden: Brill Edition.

Geeraert, J. (2016) 'Le touriste et le réfugié', Cliniques méditerranéennes, 94, 69-82.

Geeraert, J. (2018) 'Healthcare reforms and the creation of ex-/included categories of patients. 'Irregular migrants' and the 'undesirable' in the French healthcare system', International Migration, 56, 2, 68-81.

Izambert, C. (2014) 'Les Limites de L'universel. L'accès des Sans-Papiers a une Couverture Maladie en France depuis 1999', Les Cahiers du Centre Georges Canguilhem, 6, 199-215.

Juven, P-A., Pierru, F. and Vincent, F. (2019) La Casse du Siècle. A Propos des Réformes de L'hôpital Public, Paris: Raisons d'agir.

Lipsky, M. (2010) Street-Level Bureaucracy, 30th Ann. Ed.: Dilemmas of the Individual in Public Service, New York: Russell Sage Foundation.

Mbaye, E. (2009) 'Sida et immigration thérapeutique en France: mythes et réalités', Sciences sociales et santé, 27, 1, 43-62.

Mezzadra, S. and Neilson, B. (2013) Border as Method, or, the Multiplication of Labor, Durham: Duke University Press.

Petryna, A. (2002) Life Exposed: Biological Citizens after Chernobyl, Princeton: Princeton University Press. Spire, A. (2008) Accueillir ou Reconduire. Enquête sur les Guichets de L'immigration, Paris: Raisons d'agir. Willen, S. and Cook, J. (2016) 'Health-related deservingness', in F. Thomas (ed.), Handbook of Migration and Health, Cheltenham: Edward Elgar Publishing, 95-118.

Yarris, K. and Castañeda, H. (2015) 'Discourses of displacement and deservingness: interrogating distinctions between 'economic' and 'forced' migration', International Migration, 53, 3, 64-9. 